\title{
Modeling and design of reacting systems with phase transfer catalysis
}

\author{
Piccolo, Chiara; Piccione, Patrick M.; Gani, Rafiqul
}

Publication date:

2011

Document Version

Publisher's PDF, also known as Version of record

Link back to DTU Orbit

Citation (APA):

Piccolo, C., Piccione, P. M., \& Gani, R. (2011). Modeling and design of reacting systems with phase transfer catalysis. Abstract from 21st European Symposium on Computer Aided Process Engineering, Chalkidiki, Greece.

\section{General rights}

Copyright and moral rights for the publications made accessible in the public portal are retained by the authors and/or other copyright owners and it is a condition of accessing publications that users recognise and abide by the legal requirements associated with these rights.

- Users may download and print one copy of any publication from the public portal for the purpose of private study or research.

- You may not further distribute the material or use it for any profit-making activity or commercial gain

- You may freely distribute the URL identifying the publication in the public portal

If you believe that this document breaches copyright please contact us providing details, and we will remove access to the work immediately and investigate your claim. 


\section{Design of reacting systems with phase transfer catalysis}

Chiara Piccolo $^{\mathrm{a}}$, Patrick M. Piccione ${ }^{\mathrm{b}}$, Rafiqul Gani ${ }^{\mathrm{a}}$

aCAPEC-Dep. of Chem. and Biochem. Eng., Tech. Univ. of Denmark, 2800 Kgs. Lyngby, Denmark, chp@kt.dtu.dk

bProcess Studies Group, Syngenta, Jealott's Hill International Research Center, Bracknell, Berkshire RG42 6EY, United

Kingdom

Selection and design of reactive systems is an important step within the framework of conceptual process design. Most chemical processes contain both reaction and separation unit operations. The selection and design of a reactor strongly influence the conversion of reactants to desired products, as well as the selectivity. Reaction and separation processes are strongly interrelated, and optimal design takes both types of operations and their interplay into account. Accordingly, a recent trend in industry consists in preferring heterogeneous catalysis over homogeneous catalysis, largely due to the separation difficulties associated with homogeneous catalysts and which thus lead to added process stages. Multiphase catalysis involving two immiscible liquid phases can also offer a way around these problems.

A successful application of liquid-liquid multiphase catalysis is represented by Phase Transfer Catalysis (PTC). PTC is now a mature technique for synthesis of organic chemicals from two reactants located in immiscible phases. In a PTC reaction, a phase transfer catalyst is added to transfer one of the reactants from its normal phase into a different phase where it can encounter the second reactant. Despite their advantages, PTC processes encounter barriers to commercialization (such as, cost or difficulty of selection). Experimental studies have provided most of the process development information underpinning most of the industrial applications in this area. Although extremely valuable, these studies by themselves do not enable the most efficient and optimal development of the PTC technology. An a priori knowledge of PTC systems would permit a more rational process design. To date, however, the fundamental engineering information needed to complement an experimental program has been limited to a few studies on kinetic modeling of batch PTC reactions. A formal systematic approach to tackle conceptual process design problems is not available at present. A larger number of variables is present in the reaction design of a PTC reaction than for homogeneous reactions, which explains why there are no simple guidelines for the design, evaluation and optimization of PTC reaction conditions. At the same time, the higher number of degrees of freedom for fine tuning reaction conditions suggests that methodologies can be developed to further optimize PTC processes.

The objective of this study is to develop a systematic model-based framework that can be used for the design of PTC processes in conjunction with the insights obtained from experimental studies and the existing empirical knowledge. An aggregated understanding of the interplay of kinetics, mass transfer, and thermodynamics, and their effects on reactor performances will be developed. Biphasic liquid-liquid catalysis modeling is a quite complex task as it involves the consideration of reaction in both aqueous and organic phases, as well as transfer of catalyst in its active and inactive form between the phases. Challenging issues addressed in this study are the development of a reliable thermodynamic framework capable of predict reactants and products concentrations in the two different phases, as well as the estimation of catalysts' physical parameters such as partition coefficients and dissociation equilibrium constants. On basis of these fundamental physical property data, a systematic strategy for catalyst and solvent selection is proposed. Operating conditions are synthesized, analyzed, and evaluated on the basis of the reactive phase behavior. The methodology is illustrated through an interesting case study highlighting the main modeling and design issues related to PTC based reactor operations.

Key words: Phase transfer catalysis, reactor design, thermodynamic modeling, process optimization 